\title{
Neurophysiological studies on the relation between the structural properties and neurotoxicity of aliphatic hydrocarbon compounds in rats
}

\author{
J MISUMI' $^{1}$ AND M NAGANO ${ }^{2}$ \\ From the Departments of Hygiene ${ }^{1}$ and Public Health, ${ }^{2}$ Kumamoto University Medical School, \\ Kumamoto/860, Japan
}

ABSTRACT In order to determine the specific structural properties responsible for neurotoxic activity, the comparative neurotoxicity of $n$-hexane, methyl n-butyl ketone, 2,5-hexanedione, and their relatives was investigated in the peripheral nerves of rats. The maximum conduction velocity of motor and sensory fibres and the motor distal latency of the tail nerves of rats were periodically examined in animals receiving repeated subcutaneous injections of 11 aliphatic monoketone or diketone compounds and their relatives for prolonged periods. A study of the comparative neurotoxicity of $\mathbf{n}$-hexane, methyl $\mathbf{n}$-butyl ketone, and their metabolites showed that 2,5-hexanedione was the most actively neurotoxic. Furthermore, a study of other symmetrical diketones with different carbon numbers showed that 2,4-pentanedione, which is structurally similar to 2,5-hexanedione, possessed a different type of neurotoxic activity than 2,5hexanedione. Regarding aliphatic monoketone compounds, acetone, 2-pentanone, 2-heptanone, and 2-octanone were confirmed non-neurotoxic for the peripheral nervous system. Evidence from some previous reports, however, suggested that 3-heptanone, 4-octanone, and 5-nonanone might produce neuropathies by being converted to 2,5-diketones under specific conditions.

$\mathrm{N}$-hexane and methyl n-butyl ketone (MnBK) are widely used in industry and they share the metabolites, 2-hexanol and 2,5-hexanedione, in common. ${ }^{-7}$ One of these metabolites, 2,5-hexanedione, was considered to be responsible for the development of neuropathy after exposure to n-hexane or MnBK, since the histopathological changes observed in neuropathy due to 2,5-hexanedione ${ }^{8}$ were similar to those produced by $\mathrm{MnBK}^{9-12}$ or n-hexane. ${ }^{13}$

A comparative study of the neurotoxicity of hexacarbon compounds and their relatives has shown that 2,5-hexanedione was the most active neurotoxin for the peripheral nerves of rat. Investigations of the neurotoxicity of aliphatic diketone compounds by Krasavage et al ${ }^{14}$ and Spencer et al ${ }^{15}$ have shown that a specific structural property, the $\gamma$ diketone spacing, is necessary for neurotoxic activity. They termed the neuropathy due to 2,5diketones " $\gamma$-neuropathy." These results suggested

Received 1 August 1983 Accepted 22 August 1983 that it would be interesting to study the symmetrical diketones of 4-carbon or 5-carbon aliphatic compounds. A study of the neurotoxicity of 2,4pentanedione in our laboratory has shown that this compound possessed neurotoxic activity, ${ }^{16}{ }^{17}$ and that the neurotoxic activity of this compound was not distal dominant as with 2,5-hexanedione. This result suggests the necessity of a more systematic assay of 2,3-butanedione, 2,4-pentanedione, and 2,5-hexanedione because it is not clear whether or not 2,3-butanedione possesses neurotoxic activity. ${ }^{16}$ In addition, repeated injections of 2-pentanone, 2-heptanone, or 2-octanone analogous to MnBK into the backs of rats do not produce signs of peripheral neuropathy. ${ }^{18-20}$

The purpose of the present study was to compare systematically the comparative neurotoxicity of 11 aliphatic hydrocarbon compounds and their relatives including 2-pentanone, MnBK, 2-heptanone, 2-octanone, 2,3-butanedione, 2,4-pentanedione, and 2,5-hexanedione, and to investigate the specific molecular property required for neurotoxic activity in the peripheral nervous system. 
Neurophysiological studies on the relation between the structural properties and neurotoxicity of aliphatic hydrocarbon compounds in rats

Table 1 Chemical substances investigated

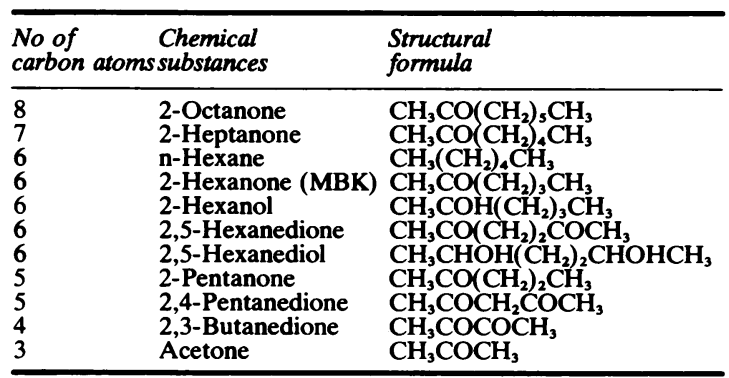

\section{Materials and methods}

A total of 142 male Donryu strain rats weighing 200-300 g were used in the study. Thirty animals were used as controls. All animals received water and a standard diet of pellets (Nihon Nosan, MR-3-A) ad libitum. Body weight, clinical condition, and food intake were examined and recorded every third day. Table 1 shows the 11 chemicals tested; all were more than $97 \mathrm{~V} / \mathrm{V} \%$ pure. Each compound was injected subcutaneously, five days a week, for periods of from 4 to 40 weeks. The daily injected dose per $\mathrm{kg}$ body weight, which ranged from 200 to $415 \mathrm{mg}$, is shown in table 2, with the total accumulated dose injected throughout the period of the experiments.

Neurological signs and the maximum conduction velocities of motor and sensory fibres (MCV and SCV) were used as indicators for estimating the effects of the aliphatic ketone compounds on the peripheral nerves of the rats. Peripheral nerve function was examined by an electrodiagnostic method described in previous reports. ${ }^{21}{ }^{22}$ Figure 1 shows

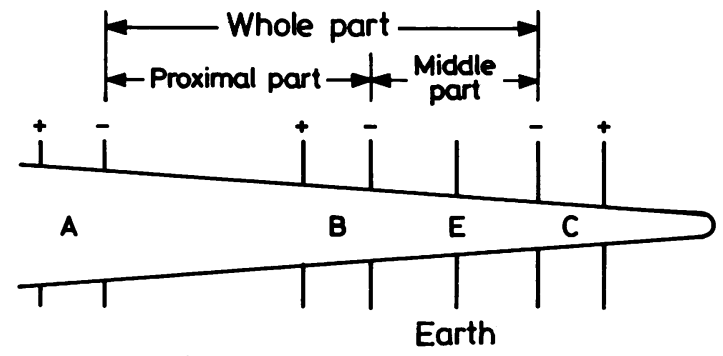

Abdominal site of the tail in rat

Fig 1 Electrode arrangement for measurement of maximum motor and sensory conduction velocities of tail nerve of rat.

schematic illustration of the electrode arrangement for the measurement of conduction velocity in the tail nerve of the rat. To stimulate the tail nerve, a pair of bare steel needles used for EEG were inserted under the skin on the ventral side of the tail. The needles were located about $2-3 \mathrm{~cm}$ from the end of the tail ( $C$ of fig 1$)$. The nerves were supramaximally stimulated with a single pulse of $0.3 \mathrm{msec}$ duration at a frequency of $1 \mathrm{~Hz}$, delivered by an electric stimulator (MNS-1101, Nohon Kohden). To record the nerve action potentials evoked in the tail nerve, two pairs of needle electrodes were inserted in the tail; one in the proximal part (A) and the other in the middle part (B) of the tail (fig 1). The distances between the stimulating and recording electrodes, and between the two recording electrodes, were measured on the skin and used for calculating the conduction velocities of the tail nerve. Muscle action potentials were also evoked by stimulation at point $\mathrm{A}$ or $\mathrm{B}$ of fig 1 , and recorded at point $\mathrm{C}$, for the measurement of maximum motor fibre

Table 2 Doses of chemicals and duration of treatment

\begin{tabular}{|c|c|c|c|c|}
\hline \multicolumn{2}{|l|}{ Chemicals } & \multicolumn{2}{|l|}{ Dose } & \multirow{2}{*}{$\begin{array}{l}\text { Duration of } \\
\text { treatment (weeks) }\end{array}$} \\
\hline & & $m g / k g / d a y$ & $\begin{array}{l}\text { Total amount } \\
\text { (g/animal) }\end{array}$ & \\
\hline $\begin{array}{l}\text { 2-Octanone } \\
\text { 2-Heptanone } \\
\text { n-Hexane } \\
\text { 2-Hexanone (MBK) } \\
\text { 2-Hexanol } \\
\text { 2,5-Hexanedione } \\
\text { 2,5-Hexanediol } \\
\text { 2-Pentanone } \\
\text { 2,4-Pentanedione } \\
\text { 2,3-Butanedione } \\
\text { Acetone }\end{array}$ & $\begin{array}{l}(n=7) \\
(n=7) \\
(n=7) \\
n=7) \\
(n=8) \\
(n=7) \\
(n=7) \\
(n=8) \\
(n=8) \\
(n=6) \\
(n=8) \\
(n=6) \\
(n=8) \\
(n=8) \\
(n=8) \\
(n=4)\end{array}$ & $\begin{array}{l}400 \\
400 \\
325 \\
415 \\
400 \\
400 \\
400 \\
300 \\
200 \\
400 \\
400 \\
200 \\
200 \\
400 \\
200 \\
400\end{array}$ & $\begin{array}{r}15 \cdot 3 \\
7 \cdot 8 \\
10 \cdot 5 \\
11 \cdot 6 \\
10 \cdot 4 \\
14 \cdot 6 \\
2 \cdot 3 \\
4 \cdot 0 \\
4 \cdot 2 \\
5 \cdot 5 \\
6 \cdot 0 \\
4 \cdot 1 \\
9 \cdot 4 \\
5 \cdot 6 \\
13 \cdot 0 \\
7 \cdot 1\end{array}$ & $\begin{array}{l}21 \\
15 \\
21 \\
21 \\
20 \\
21 \\
32 \text { days } \\
10 \\
14 \\
15 \\
9 \\
15 \\
40 \\
9 \\
40 \\
15\end{array}$ \\
\hline
\end{tabular}


conduction velocity. ${ }^{2}$ Action potentials were amplified with a time constant of $0.01 \mathrm{sec}$, and displayed on the screen of an Addscope (ATAC-250, Nihon Kohden) and recorded on graph paper by an $\mathrm{X}-\mathrm{Y}$ recorder (Yokogawa denki, 3086-22).

The skin temperature of the tail and inguinal regions was measured at the beginning of each measurement, and ranged between 36.0 and $37.5^{\circ} \mathrm{C}$ in the inguinal regions and between 32.0 and $35.0^{\circ} \mathrm{C}$ in the tail ( $\mathrm{A}, \mathrm{B}$, and $\mathrm{C}$ points of fig 1$)$. The room temperature was controlled at $29^{\circ} \mathrm{C} \pm 0.5^{\circ} \mathrm{C}$.

Statistical significance of difference between mean values for the treated and control groups was tested by Student's $t$ test.

\section{Results}

\section{CLINICAL FEATURES}

The clinical signs which were observed are summarised in table 3. All the n-hexane, MnBK, 2-hexanol 2,4-pentanedione and 2,3-butanedione treated groups showed a retardation of normal growth, and the 2,5-hexanedione and 2,5-hexanediol groups showed a loss of body weight as compared with that at the beginning of treatment. The animals treated with MnBK, 2-hexanol, 2,5-hexanediol, and 2,5hexanedione showed disturbances in gait and the 2,5-hexanediol and 2,5-hexanedione groups suffered severe paralysis of their hind limbs. The neurological signs observed in these groups have been described elsewhere. ${ }^{161723}$ In the pentanone group increased salivation in four of the eight animals was observed during the later stages of the experiment. In the 2,4-pentanedione group increased salivation on the 15th day of treatment was also observed in four of the six animals, and these four animals showed disturbances in gait on the 45th day. Thereafter, all the animals developed a spastic paralysis of the hind limbs but were not flaccid as were the animals receiving 2,5hexanedione. The other groups remained more or less normal throughout the experiments.

\section{NEUROPHYSIOLOGICAL FINDINGS}

Table 4 summarises the results of the conduction. velocities and motor distal latency in the tail nerve of the rats. As indicated in table 4, in the MnBK, 2-hexanol, 2,5-hexanediol, and 2,5-hexanedione

Table 3 General aspects and neurological signs of treated rats

\begin{tabular}{|c|c|c|c|c|c|}
\hline \multirow[t]{2}{*}{ Groups } & \multirow{2}{*}{$\begin{array}{l}\text { Effect on } \\
\text { growth }\end{array}$} & \multicolumn{4}{|c|}{ Neurological signs } \\
\hline & & $\begin{array}{l}\text { Dullness } \\
\text { in movement }\end{array}$ & $\begin{array}{l}\text { Difficulty } \\
\text { in walking }\end{array}$ & $\begin{array}{l}\text { Paralysis in } \\
\text { hind limbs }\end{array}$ & Others \\
\hline $\begin{array}{l}\text { 2-Octanone } \\
\text { 2-Heptanone } \\
\text { n-Hexane } \\
\text { 2-Hexanone (MBK) } \\
\text { 2-Hexanol } \\
\text { 2,5-Hexanedione } \\
\text { 2,5-Hexanediol } \\
\text { 2-Pentanone } \\
\text { 2,4-Pentanedione } \\
\text { 2,3-Butanedione } \\
\text { Acetone }\end{array}$ & $\begin{array}{l}- \\
- \\
+ \\
+ \\
+ \\
+ \\
++ \\
+ \\
+ \\
+ \\
+\end{array}$ & $\begin{array}{l}- \\
- \\
+ \\
+ \\
+ \\
+ \\
+ \\
\pm \\
+ \\
\pm \\
+\end{array}$ & $\begin{array}{l}- \\
- \\
\overline{+} \\
+ \\
++ \\
++ \\
+ \\
+ \\
-\end{array}$ & $\begin{array}{l}- \\
- \\
- \\
- \\
+ \\
+ \\
- \\
- \\
-\end{array}$ & $\begin{array}{l}- \\
- \\
\text { Salivation } \\
\text { Salivation } \\
\text { Incontinence } \\
\text { Salivation } \\
\text { Salivation } \\
\text { - } \\
\text { - }\end{array}$ \\
\hline
\end{tabular}

$-=$ Negative, $\pm=$ slight, $+=$ moderate, ++ = severe or pronounced.

Table 4 Effect of the compounds tested on the nerve conduction velocity and motor distal latency (ratios to the controls)

\begin{tabular}{|c|c|c|c|c|c|}
\hline \multirow[t]{2}{*}{ Chemicals } & \multirow{2}{*}{$\begin{array}{l}\text { Motor } \\
\text { conduction } \\
\text { velocity }\end{array}$} & \multicolumn{3}{|c|}{ Sensory conduction velocity } & \multirow[t]{2}{*}{ Distal latency } \\
\hline & & Whole & Proximal & Distal & \\
\hline $\begin{array}{l}\text { 2-Octanone } \\
\text { 2-Heptanone } \\
\text { n-Hexane } \\
\text { 2-Hexanone (MBK) } \\
\text { 2-Hexanol } \\
\text { 2,5-Hexanedione } \\
\text { 2,5-Hexanediol } \\
\text { 2-Pentanone } \\
\text { 2,4-Pentanedione } \\
\text { 2,3-Butanedione } \\
\text { Acetone }\end{array}$ & $\begin{array}{c}100 \\
100 \\
98 \\
60^{* *} \\
54^{* *} \\
40^{* *} \\
65^{* *} \\
108 \\
81^{* *} \\
99 \\
98\end{array}$ & $\begin{array}{c}102 \\
96 \\
96 \\
68^{* *} \\
66^{* *} \\
52^{* *} \\
55^{* *} \\
99 \\
90^{* *} \\
94 \\
100\end{array}$ & $\begin{array}{c}101 \\
98 \\
100 \\
81^{* *} \\
73^{* *} \\
61^{* *} \\
65^{* *} \\
101 \\
93^{* *} \\
96 \\
99\end{array}$ & $\begin{array}{l}103 \\
95 \\
94 \\
56^{* *} \\
59^{* *} \\
44^{* *} \\
46^{* *} \\
99 \\
80^{* *} \\
90^{*} \\
99\end{array}$ & $\begin{array}{l}92 \\
128 \\
136 \\
190^{* *} \\
165^{* *} \\
282^{* *} \\
350^{* *} \\
125 \\
134 \\
133 \\
121\end{array}$ \\
\hline
\end{tabular}

Numerals indicate ratios of respective mean values of $400 \mathrm{mg} / \mathrm{kg} /$ day groups (2,4-pentanedione group, $200 \mathrm{mg} / \mathrm{kg} /$ day) to mean values of controls $(100)$ in the most advanced stages of neuropathy or in last stage of experiments.

Significance level: ${ }^{*} p<0.05,{ }^{* *} p<0.01$, as compared with values of controls by $t$ test.

Whole, proximal, and distal indicate the whole (A-C in fig 1), proximal (A-B), and distal (B-C) parts of the tail nerve in rats. 
Neurophysiological studies on the relation between the structural properties and neurotoxicity of aliphatic hydrocarbon compounds in rats

groups both the MCVs and SCVs decreased significantly as compared with the control values. The amplitudes of the nerve action potentials also decreased and the motor distal latency was prolonged. Nevertheless, the n-hexane group treated with $325 \mathrm{mg} / \mathrm{kg}$ for 21 weeks exhibited no significant decrease in conduction velocity, although decreased amplitude of the nerve action potentials was observed in the last stage of the experiment.

In the 2,4-pentanedione group slowing of the MCVs and SCVs was observed at the 8 to 10 week stage of the experiments. As indicated in table 4, in the 2,3-butanedione group, when $400 \mathrm{mg} / \mathrm{kg}$ of the compound was given to the animals for nine weeks, slowing of the SCVs was produced in the last stage of the experiment. Nevertheless, repeated injections of $200 \mathrm{mg} / \mathrm{kg}$ of the compound produced no changes in the conduction velocities, motor distal latency, and action potentials despite the treatments continuing for 40 weeks. In the pentanone group a retardation in the SCVs was observed only at the first measurement even though treatments with the compound were continued for nine weeks. The other groups showed no electrophysiological change.
RELATIONS BETWEEN THE MEAN TOTAL DOSE PER ANIMAL AND A SLOWING OF CONDUCTION VELOCITY

In order to compare the potency of neurotoxic activity of the chemical substances being tested, the mean accumulated total doses at that time when a significant slowing in conduction velocity began to be observed, were investigated. Table 5 summarises the relations between the mean total doses $(\mathrm{g})$ per animal for the respective compounds and the slowing of conduction velocities.

In the 2,5-hexanedione group the time of the onset of a slowing in conduction velocity was dose dependent-that is, in the group receiving a dose of $400 \mathrm{mg} / \mathrm{kg} /$ day an accumulated mean total dose of less than $1.4 \mathrm{~g}$ of the compound produced a slowing in conduction velocity. In the group in which the daily dose was $300 \mathrm{mg} / \mathrm{kg}$, a mean total dose of $2.1 \mathrm{~g}$ produced a significant slowing in conduction velocity, and in the group receiving a daily dose of 200 $\mathrm{mg} / \mathrm{kg}$ the same result began to be observed when the mean total dose was about $2.4 \mathrm{~g}$.

In the MBK group a slowing in conduction velocity occurred when the mean total dose of the com-

Table 5 Relationships between mean total doses per animal and slowing of conduction velocity

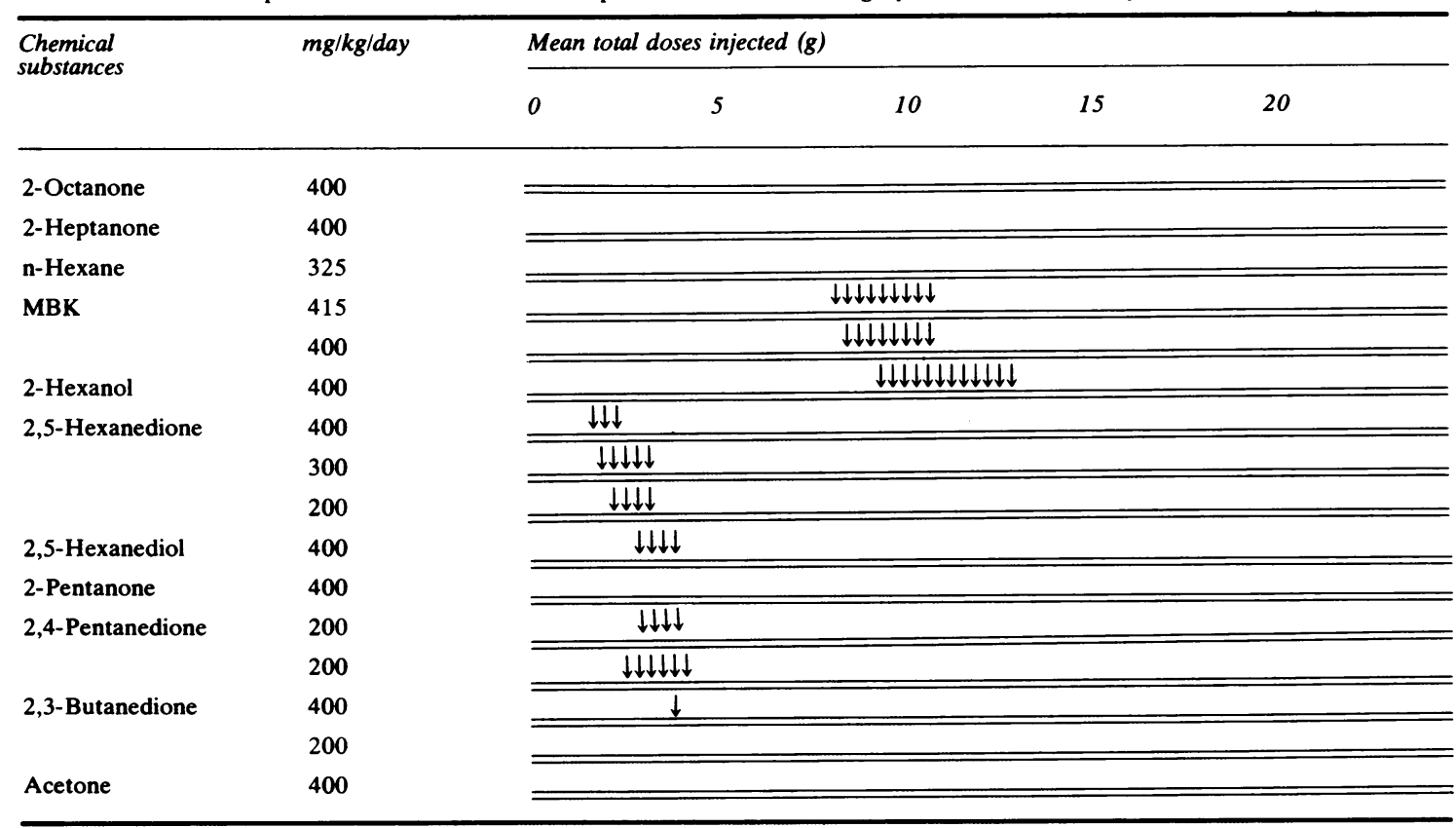

Arrows $(\downarrow \downarrow \downarrow)$ indicate a significant slowing in conduction velocity, as compared with the controls by the $t$ test. 
pound reached 6-7 $\mathrm{g}$; in the 2-hexanol group this took place after $9.6 \mathrm{~g}$ of the compound had been injected and in the 2,5-hexanediol group after $4.0 \mathrm{~g}$ had been administered. The time of onset of the slowing of the SCVs in the 2,4-pentanedione group was approximately similar to that in the 2,5hexanedione group, but a retardation in the MCVs was observed after a total dose of $2.9 \mathrm{~g}$, which was greater than that of the 2,5-hexanedione group.

\section{Discussion}

The present study has confirmed two points: firstly, 2-hexanol, 2,5-hexanediol, 2,5-hexanedione, intermediate metabolites of $n$-hexane, and MnBK are all neurotoxic. Secondly, the neurotoxic potency among the five hexacarbon compounds shown in table 1 may be ranked in the order 2,5-hexanedione, 2,5-hexanediol, MnBK, 2-hexanol, and n-hexane. Figure 2 shows the relative neurotoxicity of n-hexane, MnBK, and their metabolites. The ratio of the mean total dose of the respective compounds required to produce a decrease in the conduction velocity similar to that of MnBK was calculated in the form of a neurotoxic index in which the neurotoxicity of $\mathrm{MnBK}$ was regarded as $1 \cdot 0$. The neurotoxic indices of 2,5-hexanedione, 2,5hexanediol, 2-hexanol, and n-hexane were $4 \cdot 6,1 \cdot 6$, 0.68 , and less than 0.58 (fig 2). This agrees with the results obtained by Krasavage et al in their investigation of the number of days it took to develop neuropathy ${ }^{14}$ The animals treated with daily doses of $200 \mathrm{mg} / \mathrm{kg}$ of 2,4-pentanedione exhibited clinical and neurophysiological evidence of neuropathy, but repeated subcutaneous injections of $400 \mathrm{mg} / \mathrm{kg} / \mathrm{day}$ of the compound caused the deaths of all seven animals and were accompanied by increased salivation, convulsions, and ataxia of hind limbs; no animals died as the result of repeated injections of equivalent amounts of 2,5-hexanedione. It is difficult to compare the neurotoxic potency of 2,4pentanedione with that of 2,5-hexanedione because the type of neurotoxicity of 2,4-pentanedione seems to differ from that of 2,5-hexanedione. But, considering only the peripheral nerves, the neurotoxicity of this compound seems to be less than that of 2,5hexanedione, whereas its neurotoxic activity in the central nervous system is greater than that of 2,5hexanedione.

The compound 2,3-butanedione was considered non-neurotoxic because, in this group of animals, no definite slowing in the conduction velocity of the tail nerve was observed. The decreased conduction velocity seen in the last stage of the experiment in which daily doses of $400 \mathrm{mg} / \mathrm{kg}$ were given was considered to be due to the low haemoglobin levels seen

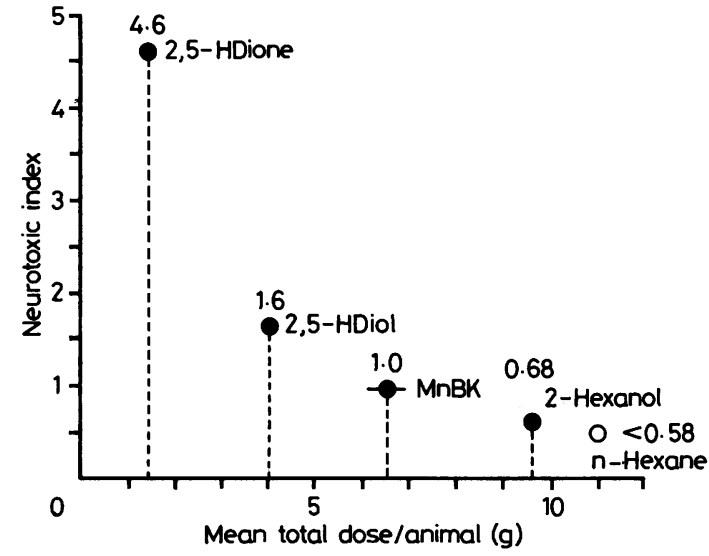

Fig 2 Relative neurotoxicity of n-Hexane, $M n B K$, and their metabolites. Horizontal axis indicates mean total dose (g) per animal needed to produce a significant decrease in conduction velocity in the groups treated with daily doses of $400 \mathrm{mg} / \mathrm{kg}$ of each compound as compared with the control value. Vertical axis indicates the neurotoxicity of the respective groups relative to $\mathrm{MnBK}(1 \cdot 0)$.

in the animals. They also had severe ulcers accompanied by pustules in the injected sites on their backs; no neurological signs were produced throughout the experiment. In addition, repeated daily injections of $200 \mathrm{mg} / \mathrm{kg}$ of the compound showed no evidence of neuropathy throughout the experiment over a period of 40 weeks.

Spencer et al have also compared the neurotoxicity of aliphatic diketone compounds and their related compounds 3,5-heptanedione, 2,4hexanedione, 2,5-hexanedione, 2,3-hexanedione, 1,6-hexanediol, 2-heptanone, glutaraldehyde, 1,4butanediol, and acetone. ${ }^{15}$ They have reported that only animals treated with 2,5-hexanedione or 2,5hexanediol exhibit neurological signs and pathological changes identical to those seen with exposure to n-hexane or MnBK. Johnson et al have also found 2-heptanone to be non-neurotoxic to rats and monkeys. ${ }^{25}$

In the present study none of the groups treated with 2-octanone, 2-heptanone, 2-pentanone, and acetone showed any appreciable clinical or neurophysiological evidence of neuropathy, although increased salivation was observed in the 2-pentanone group. Our finding that 2-heptanone or acetone possesses no neurotoxic activity agrees with the results of Johnson et al. ${ }^{25} \mathrm{O}^{\prime}$ Donoghue et al have reported that a symmetrical diketone compound, 2,6-heptanedione, which is produced by oxidation at the sixth carbon of 2-heptanone was not neurotoxic, ${ }^{26}$ and Altenkirch et al have reported that methyl ethyl ketone (MEK) potentiates the 
Neurophysiological studies on the relation between the structural properties and neurotoxicity of aliphatic hydrocarbon compounds in rats

Table 6 Relationships between structural properties and neurotoxic activity of aliphatic hydrocarbon compounds investigated up to the present

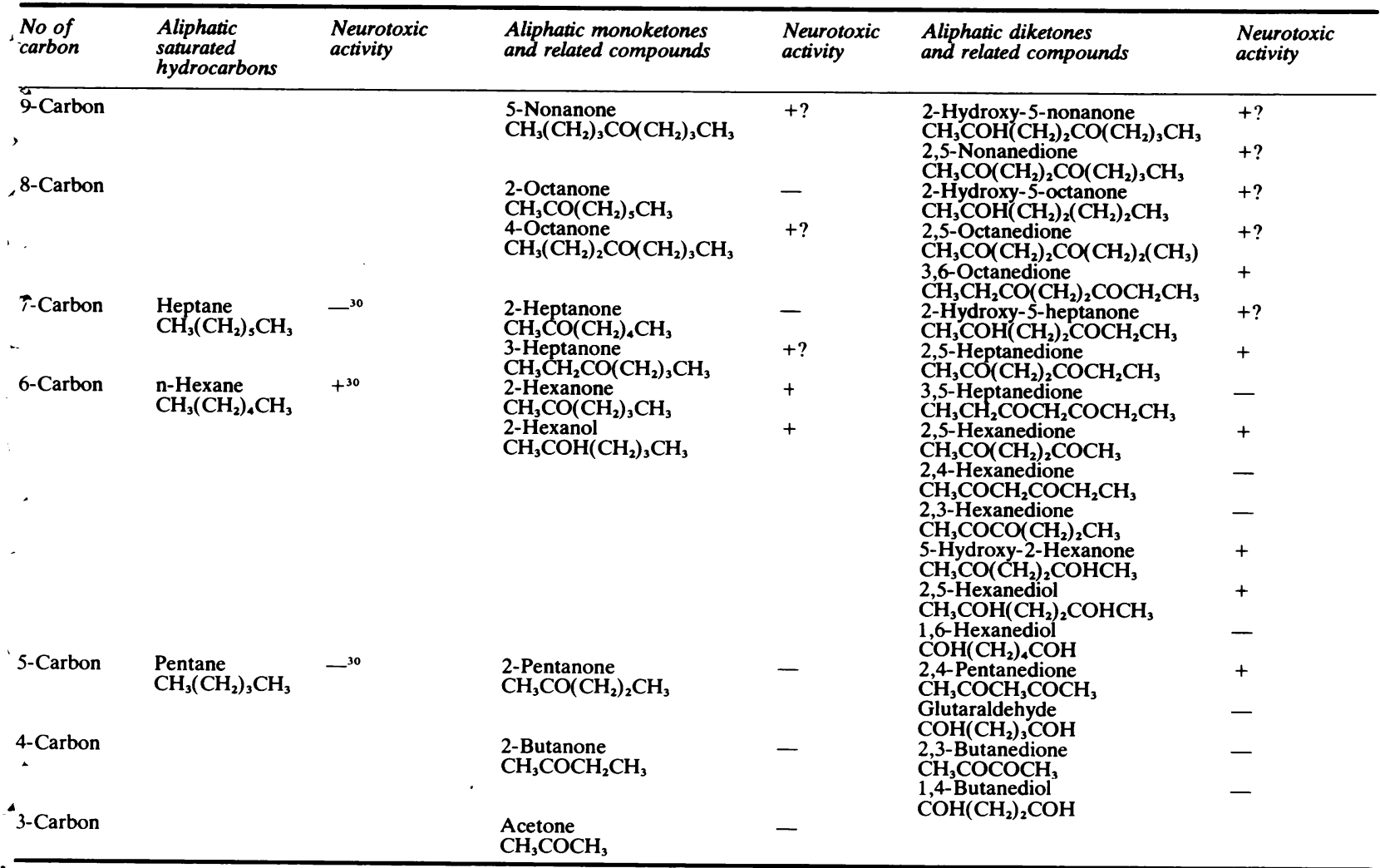

neurotoxicity of $\mathbf{n}$-hexane, but does not itself produce a neuropathy. ${ }^{27}$ Thus with the exception of $\mathrm{MnBK}$ the aliphatic monoketone compounds $\left(\mathrm{C}_{3}-\right.$ $\mathrm{C}_{8}$ ) which have a carbonyl group at the second carbon do not appear to be neurotoxic to the peripheral nervous system.

A monoketone such as ethyl n-butyl ketone (EBK), however, may produce neuropathy since Katz et al have found 2,5-heptanedione to produce the same type of neurotoxicity as seen with 2,5hexanedione ${ }^{28}$ For the same reason, O' Donoghue et al have suggested that 5-nonanone, potentiated by 5-methyl-2-octanone, may be converted to 2,5nonanedione, $\mathrm{MnBK}$, and 2,5-hexanedione and is, therefore, neurotoxic. ${ }^{29}$ These findings suggest that the neurotoxicity of 4-octanone should be investigated since it may be converted to 2,5-octanedione via 2-hydroxy 5-octanone.

The results of the present study, and some from earlier studies, are summarised in table 6. Monoketone compounds which may be expected to be converted to 2,5-diketone are neurotoxic and in addition, it has been found that 2,4-pentanedione is also neurotoxic. 2,4-Pentanedione forms chelates with copper, iron and cobalt and this ability to chelate with metals might be concerned with the development of neuropathy by interfering with coenzymes. For this reason it seems important to investigate whether or not this property is generally related to neurotoxic activity.

We are much indebted to Professor S Nomura and Professor $\mathrm{H}$ Miura for their valuable advice and support in carrying out the experiment. Part of this study was supported by a grant from the Ministry of Education, Japan.

\section{References}

' Raleigh RL. Toxicity of methyl n-butyl ketone. Arch Environ Health 1975;30:317-8

${ }^{2}$ Abdel-Rahman MS. Toxicity and metabolism of methyl n-butyl ketone. Am Ind Hyg Assoc J 1976;37:95-102.

${ }^{3}$ DiVincenzo GD, Caplan CJ, Dedinas J. Characterization of the metabolism of methyl n-butyl ketone, methyl iso-butyl ketone 
and methyl ethyl ketone in guinea pig serum and their clearance. Toxicol Appl Pharmacol 1976;36:511-22.

4 DiVincenzo GD, Hamilton ML, Caplan CJ, Dedinas J. Metabolic fate and disposition of ${ }^{14} \mathrm{C}$-labeled methyl $\mathrm{n}$-butyl ketone in the rat. Toxicol Appl Pharmacol 1977;41:547-60.

${ }^{5}$ Perbellini L, Degrandis D, Semenzato F, Rizzato N, Simonti A. An experimental study on the neurotoxicity of $n$-hexane metabolites: hexanol-1 and hexanol-2. Toxicol Appl Pharmacol 1978;46:421-7.

- Couri D, Abdel-Rahman MS, Hetland LB. Biotransformation of $\mathrm{n}$-hexane and methyl $\mathrm{n}$-butyl ketone in guinea pigs and mice. Am Ind Hyg Assoc J 1978; 39:295-300.

' Perbellini L, Brugnone F, Pastorello G, Grigolini L. Urinary excretion of $\mathbf{n}$-hexane metabolites in rats and human. Int Arch Occup Environ Health 1979;42:349-54.

${ }^{8}$ Spencer PS, Schaumburg HH. Experimental neuropathy produced by 2,5-hexanedione-a major metabolite of the neurotoxic industrial solvent methyl n-butyl ketone. J Neurol Neurosurg 1975;38:771-5.

9 Mendell JR, Saida K, Ganansia MF, et al . Toxic polyneuropathy produced by methyl n-butyl ketone. Science $1974 ; 185: 787-9$.

${ }^{10}$ Spencer PS, Schaumburg HH, Raleigh RL, Terhaar CJ. Nervous system degeneration produced by the industrial solvent methyl n-butyl ketone. Arch Neurol 1975;32:219-22.

"Allen N, Mendell JR, Billmaier DJ, Fontaine RE, O'Neill J. Toxic polyneuropathy due to methyl n-butyl ketone. An industrial outbreak. Arch Neurol 1975;32:209-18.

${ }_{12}$ Saida K, Mendell JR, Weiss HS. Peripheral nerve changes induced by methyl $\mathbf{n}$-butyl ketone and potentiation by methyl ethyl ketone. J Neuropathol Exp Neurol 1976;35:207-25.

${ }^{13}$ Schaumburg HH, Spencer PS. Degeneration in central and peripheral nervous systems produced by pure $n$-hexane: an experimental study. Brain 1976;99:183-92.

${ }^{14}$ Krasavage WJ, O’Donoghue JL, DiVincenzo GD, Terhaar CJ. The relative neurotoxicity of methyl n-butyl ketone, $n$-hexane and their metabolites. Toxicol Appl Pharmacol $1980 ; 52: 433-41$.

is Spencer PS, Bishoff MC, Schaumburg HH. On the specific molecular configuration of neurotoxicity aliphatic hexacarbon compounds causing central peripheral distal axonopathy. Toxicol Appl Pharmacol 1978;44:17-28.

${ }^{16}$ Misumi J, Kawakami M, Nomura S. An electrophysiological study on the relationships between $(\omega-1)$ oxidation of straight-chain hydrocarbons (C:5-7) and peripheral neuropathy in rats. Proceedings of 9th Asian conference on occupational health, Seoul. Korea: Office of the Asian Association of Occupational Health, 1979:129-33.

${ }^{17}$ Misumi J, Kawakami M, Nomura S. Experimental studies on the relationships between molecular configuration and neurotoxicity of aliphatic hydrocarbon compounds. Proceedings of the 8 th international conference of occupational health in the chemical industry, Tokyo. Tokyo: Aikawa Shobo Publishing Co., 1980:141-6.
${ }^{18}$ Misumi J, Kawakami M, Tsubaki K, Satake K, Nomura S. Effects of 2,5-hexanediol, acetyl acetone and 2-hentanone on the conduction velocity of tail nerves in rat. The 52nd annual meetings of Japanese industrial hygiene association, Tokyo 1979. Tokyo: Japan Association of Industrial Health. (In Japanese.)

19 Kawakami M, Misumi J, Nomura S. Effects of 2,3-butanedione, 2-pentanone and 2,5-hexanedione on the conduction velocity of tail nerves in rats. 53rd annual meetings of Japanese industrial hygiene association, Sendai, 1980. Tokyo: Japan Association of Industrial Health. (In Japanese.)

${ }^{20}$ Misumi J, Nagano M, Nomura S. Experimental study on the neurotoxicity of 2-octanone and 2-hexanol a n-hexane metabolite. Jpn J Ind Health 1982;24:475-84.*

${ }^{21}$ Misumi J, Nomura S. An electrophysiological method for examination in vivo of peripheral neuropathy due to organic mercury poisoning in rats. Arh Hig Rada Toksikol 1979;(suppl):239-43.

${ }^{22}$ Misumi J. Electrophysiological studies in vivo on peripheral nerve function and their application to peripheral neuropathy produced by organic mercury in rats. II Measurement of the maximum conduction velocity of compound action potentials in the tail nerve of healthy rats. Kumamoto Med J 1979;32:1-14.

${ }^{23}$ Nagano M, Misumi J, Nomura S. An electrophysiological study on the peripheral neurotoxicity of 2,3-butanedione, 2,4pentanedione and 2,5-hexanedione in rats. Jpn J Ind Health 1983;25:471-82.*

24. Fullerton PM. Chronic peripheral neuropathy produced by lead poisoning in guinea pigs. J Neuropathy Exp Neurol 1966;25:214-36.

${ }^{25}$ Johnson BL, Setzer JV, Lewis TR, Hornung RW. An electrodiagnostic study of the neurotoxicity of methyl n-amyl ketone. Am Ind Hyg Assoc J 1978;39:866-72.

${ }^{26}$ O' Donoghue JL, Krasavage J. Hexacarbon neuropathy: A r-diketone neuropathy? J Neuropathol Exp Neurol 1979;38:333.

${ }^{27}$ Altenkirch H, Stoltenburg G, Wagner HM. Experimenta studies on hydrocarbon neuropathies indued by methyl-ethyl-ketone (MEK). J Neurol 1978;219:159-70.

${ }^{28}$ Katz GV, O' Donoghue JL, DiVincenzo GD, Terhaar CJ. Comparative neurotoxicity and metabolism of ethyl $n$-butyl ketone in rats. Toxicol Appl Pharmacol 1980;52:153-8.

${ }^{29}$ O' Donoghue JL, Krasavage WJ, DiVincenzo GD, Ziegler DA. Commercial-grade methyl heptyl ketone (5-methyl-2octanone). Neurotoxicity: contribution of 5-nonanone. Toxicol Appl Pharmacol 1982;62:307-16.

${ }^{30}$ Takeuchi Y, Ono Y, Hisanaga N, Kitoh J, Sugiura Y. A comparative study on the neurotoxicity of n-pentane, $n$-hexane, and n-heptane in the rat. Br J Ind Med 1980;37:241-7.

*In Japanese with English abstract. 